\title{
Contribuições da Psicologia Brasileira para o Estudo da Surdez
}

\author{
Contributions of Brazilian Psychology to the Study of Deafness
}

\author{
Cláudia A. Bisol ${ }^{a, b}$, Janaína Simioni $^{b}$ \& Tânia Sperb ${ }^{* a}$ \\ ${ }^{a}$ Universidade Federal do Rio Grande do Sul, Porot Alegre, Brasil \\ ${ }^{b}$ Universidade de Caxias do Sul, Caxias do Sul, Brasil
}

\begin{abstract}
Resumo
Este trabalho apresenta as contribuições da psicologia brasileira para o estudo da surdez. Realizou-se uma revisão em periódicos nacionais qualis A, B e C, sendo que um total de 34 artigos foi selecionado e analisado segundo o conceito de surdez, a temática central e o tipo de publicação. Os principais resultados, referentes a publicações entre 1995 e 2005, indicam que: (a) o conceito socioantropológico de surdez prevalece entre os pesquisadores brasileiros; (b) as temáticas de maior interesse são a linguagem e a língua, o desenvolvimento cognitivo e relações familiares; (c) foram encontrados 15 artigos de revisão de literatura, 16 de relatos de pesquisa empírica e 3 de relato de experiência. Discute-se a necessidade de ampliar a produção científica na área.

Palavras-chave: Psicologia; surdez; deficiência auditiva

Abstract

This article presents the contributions of Brazilian Psychology to the study of deafness. National journals, categories A, B, and C were reviewed and 34 articles were selected and analyzed considering the concept of deafness, the core issue and the kind of publication. The main results, concerning the publications made between 1995 and 2005 show that: (a) the socio-anthropologic concept of deafness prevails among Brazilian researchers; (b) the issues of main interest are language, cognitive development and family relations; (c) 15 of the articles found were literature reviews, 16 were empirical research reports and 3 were reports of practical experiences. This article discusses the need of increasing the scientific production in this area of study.

Keywords: Psychology; deafness; hearing impairment.
\end{abstract}

Este artigo tem por objetivo traçar um panorama das contribuições da psicologia brasileira para o estudo da surdez. Este tipo de pesquisa bibliográfica, denominada de pesquisas de estado da arte, é realizada diante da necessidade de mapear e discutir a produção acadêmica em determinado campo do conhecimento ou período histórico. Com um caráter inventariante mas também descritivo, esse tipo de estudo permite destacar os aspectos negligenciados ou privilegiados da produção científica, numa tentativa de organizar e gerar bases de dados para futuras pesquisas (Bariani, Buin, Barros, \& Escher, 2004; Ferreira, 2002).

Nas últimas décadas existe um esforço no Brasil para ampliar e qualificar a produção científica e sua divulgação através de periódicos que obedecem a padrões mais rígidos de publicação e adquirem, aos poucos, maior circulação e receptividade nos meios acadêmicos. Este esforço inclui a psicologia, embora algumas áreas muito específicas apresentem ainda uma produção mais limitada ou esparsa. Este é, provavelmente, o caso da área da surdez. Por isto apresenta-se esta proposta de analisar as contribuições dos pes-

* Endereço para correspondência: Universidade Federal do Rio Grande do Sul, Instituto de Psicologia, Rua Ramiro Barcelos, 2600, PortoAlegre, RS, 90035-003.E-mails: sperbt@terra.com.br, claudiabisol@terra.com.bre janasimioni@yahoo.com.br quisadores nesta área específica a partir do estudo de artigos publicados em periódicos científicos nacionais.

O interesse da psicologia pela surdez tem já um longo percurso no cenário internacional. Em um artigo destinado a fazer uma retrospectiva dos 100 anos da psicologia e surdez nos Estados Unidos, publicado no início da década de 90, Pollard (1993) escreve:

Se você fosse um psicólogo há 100 anos atrás, você procuraria pelas publicações de seu estimado contemporâneo, William James. Você teria lido sua publicação mais recente no 'The American Annals of the Deaf', na qual ele desafia a noção prevalecente de que a língua formal é necessária para o pensamento abstrato. Se você fosse um leitor regular dos Anais, você poderia também ter visto o trabalho de David Greenberger que, duas décadas antes da publicação da escala de Binet, descreveu procedimentos objetivos para a avaliação das habilidades intelectuais das crianças surdas. (Pollard, 1993, p. 32).

O interesse da psicologia pela surdez está muito relacionado com o desenvolvimento na área da educação de surdos. O Brasil começou a sistematizar a educação para os surdos em 1857 através da vinda do professor francês Hernest Huet, surdo, a convite de D. Pedro II. Neste ano, foi fundada a primeira escola para meninos surdos, o Im- 
perial Instituto de Surdos Mudos, atualmente Instituto Nacional de Educação de Surdos - INES.

Um debate acirrado divide os educadores, profissionais da saúde e pesquisadores desde o século XVIII até os dias de hoje: o abade L'Epée, fundador em Paris da primeira escola pública para os surdos, utilizava a língua de sinais como meio para ensinar a língua e cultura francesas para os surdos; em contrapartida, Heinicke, em Leipzig, defendia um enfoque exclusivamente oral: "A discussão mantida por meio de correspondência escrita entre L'Epée e Heinicke no final do século XVIII pode ser considerada como o começo de uma controvérsia inacabada entre o método oral e o manual" (Marchesi, 1993, p. 182). No século XIX, a defesa do método oral foi liderada, nos Estados Unidos, por Alexander Graham Bell e muito praticada na Europa, já os proponentes da língua de sinais eram representados principalmente por Edward Gallaudet (Pollard, 1993). Os métodos orais predominaram nas propostas educativas a partir do Congresso de Milão realizado em 1880. No século XX, é nos anos 60 que gradativamente a língua de sinais retorna ao cenário da educação (Ducharme \& Mayberry, in press; Marchesi, 1993; Skliar, 1997).

A discussão entre os defensores da oralização e os defensores da língua de sinais se relaciona a dois modelos de surdez que tendem a caracterizar as pesquisas na área: o clínico-terapêutico e o socioantropológico (Skliar, Massone, \& Veinberg, 1995). O modelo clínico-terapêutico, preocupado principalmente com o diagnóstico e a reabilitação, reforça a visão da educação como método reabilitador colocado em cena a partir do diagnóstico médico, orientando a atenção para a cura do problema auditivo, correção de defeitos da fala e treinamento de habilidades como leitura labial (Skliar, 1997). O esforço dirige-se para a normalização do indivíduo e sua adaptação à sociedade a partir de critérios geralmente fixos do que seja normalidade. Os comportamentos e valores dos ouvintes tendem a ser tomados como norma, a diferença é geralmente percebida como negativa e caracterizada como desvio. A aprendizagem da língua oral é o principal objetivo das intervenções educacionais e terapêuticas (Skliar et al., 1995).

O modelo socioantropológico propõe que a surdez seja vista como uma diferença cultural e lingüística: muitos surdos não consideram a si mesmos como deficientes, mas pertencentes a uma minoria lingüística. Segundo Padden e Humphries:

. . . 'deficiência' é um rótulo que historicamente não pertence às pessoas Surdas. Sugere auto-representações políticas e objetivos que não são familiares ao grupo. Quando pessoas Surdas discutem sua surdez, usam termos profundamente relacionados a sua língua, seu passado, e sua comunidade. As pessoas surdas têm uma história de aliançar-se a outros grupos deficientes, mas não é um termo primário de auto-identificação . . (1988, p. 44).

Esse enfoque à questão da surdez encontra suporte nas tentativas mais recentes de não ver a deficiência como uma tragédia individual a ser medicalizada e comparada em pesquisas com o corpo não deficiente da maior parte da população. Na educação dos surdos, a conseqüência da perspectiva socioantropológica é a defesa do bilingüismo em contraposição ao oralismo. Segundo Ducharme e Mayberry (in press), a educação bilíngüe iniciou na Suécia no início dos anos 80, através da adoção de uma política nacional: todas as crianças surdas passaram a utilizar a Língua Sueca de Sinais como primeira língua, passaram a ter professores surdos e a aprender a língua sueca como uma segunda língua, para ler e escrever. O ingresso do bilingüismo no Brasil ocorreu no início da década de 90 , junto a uma luta da comunidade surda pela valorização de seus direitos, cultura e comunidade (Meirelles \& Spinillo, 2004). A Língua Brasileira de Sinais (Libras) foi reconhecida como língua oficial no país no ano de 2002.

Estas considerações introdutórias permitem situar a análise das publicações brasileiras, pois na psicologia ocorre o mesmo que nas demais áreas que se dedicam à surdez: há pesquisadores que defendem a oralização dos surdos, outros argumentam a favor da língua de sinais e do bilingüismo. Os primeiros geralmente identificam-se com modelo clínico-terapêutico de surdez, enquanto que os segundos defendem a concepção socioantropológica. Pretende-se com este estudo ver de que forma os psicólogos brasileiros têm dado atenção a esta área, se há ou não um modelo que prevalece quanto ao conceito de surdez, quais os temas que têm despertado maior interesse e os tipos de trabalho que têm sido publicados. A partir disso, pode-se discernir quais as áreas mais exploradas e quais as áreas pouco contempladas pela pesquisa nacional.

\section{Método}

Na realização da pesquisa bibliográfica, foram utilizadas três estratégias: (a) busca computadorizada no Portal SciELO (http://www.scielo.br), com os termos surdo, surda, surdos, surdas, surdez, necessidades especiais e deficiência. Uma checagem foi realizada com os mesmos descritores no PsychINFO (http://psycinfo.apa.org/ psycarticles/direct/), sem sucesso; (b) busca através da lista divulgada pela Coordenação de Aperfeiçoamento de Pessoal de Nível Superior - CAPES (http://servicos. capes.gov.br/webqualis/), onde constam, por área, as revistas qualis A,B e C. As revistas das áreas de psicologia, educação, letras e lingüística foram revisadas por título do periódico em meio eletrônico, pois algumas não estão indexadas no Portal SciELO; e (c) busca manual em periódicos das áreas de psicologia, educação e letras em bibliotecas de duas universidades (Universidade Federal do Rio Grande do Sul e Universidade de Caxias do Sul).

Para o presente estudo, foram incluídos somente os artigos publicados em periódicos brasileiros que obtiveram qualis A, B e C na atualização da CAPES (2004); artigos cuja temática fosse pertinente a área da psicologia ou à interface da psicologia com áreas afins (medicina, educação, lingüística, fonoaudiologia, etc.); e artigos nos quais pelo menos um dos autores tivesse formação em psicologia. Não foi feita restrição quanto à data da publicação. Um total de 231 artigos foram revisados. Destes, 34 foram selecionados a partir dos três critérios de inclusão mencionados. Apenas um artigo escrito por uma pesquisadora cuja 
área é a lingüística foi incluído, pois sua contribuição para a compreensão do desenvolvimento cognitivo do surdo é evidente e seu trabalho é referência para muitos pesquisadores psicólogos.

Os 34 artigos selecionados (Tabela 1) foram lidos na íntegra e analisados segundo as categorias: conceito de sur- dez, temática de maior interesse e tipo de publicação (relato de pesquisa empírica, relato de experiência ou revisão da literatura). Para complementar a análise destas três categorias, fez-se um breve levantamento das principais referências bibliográficas utilizadas e das conclusões mais relevantes.

Tabela 1

Artigos Publicados Selecionados para Análise

Ano Título Autor(es)

1995 O raciocínio lógico-dedutivo do surdo que se utiliza da linguagem gestual ou oral.

1995 Educação especial, psicologia do surdo e bilingüismo: Bases históricas e perspectivas atuais.

1996 O ingresso da criança surda na escola de primeiro grau Concepções e expectativas de pais e profissionais.

1997 A linguagem e seus efeitos no desenvolvimento cognitivo e emocional da criança surda.

1997 Integração do sujeito ao processo educativo na realidade contemporânea: Um estudo com adolescentes surdos.

1997 Da psicanálise à surdez - Uma escuta psicanalítica em instituição escolar para surdos.

1998 O implante coclear como ferramenta de desenvolvimento lingüístico da criança surda.

1998 Sujeito surdo e profissionais ouvintes: Repensando esta relação.

1998 A surdez enquanto marca constitutiva.

1999 A surdez na dinâmica familiar: Estudo de uma população específica

1999 Crianças surdas e suas famílias: Um panorama geral. Reflexão sobre um trabalho com famílias.

SignWriting: Implicações psicológicas e sociológicas de uma escrita visual direta de sinais, e de seus usos na educação do surdo.

2000 Metacognição: Um caminho para ultrapassar os limites da audição.

2001 Expectativas prévias ao implante coclear e avaliação após implante em adolescentes

2001 Musicoterapia e surdez: A reação de surdos aos instrumentos musicais.

2001 Repercussões da surdez na criança, nos pais

e suas implicações no tratamento.

2002 Um olhar psicanalítico a respeito da questão da identidade do surdo.

2003 A lingua de sinais e a escrita - Possibilidades de se dizer, para o surdo.

2003 Era uma vez...: Narrativas literárias em língua de sinais como fator de desenvolvimento.

2003 Violência psíquica e surdez - Os caminhos de um (des)encontro.

2003 A repetição intergeracional e o significado atual da deficiência auditiva.
Cordeiro, A. A., \& Dias, M. G.

Souza, R. M.

Batista, C. G., \& Silva, A. B.

Reis, V. P.

Dupret, L.

Geovanini, F. C.

Capovilla, F. C.

Souza, R. M.

Solé, M. C. P.

Dias, T. R., Mantelatto, S. A., Prette, A.

D., Pedroso, C. C., Gonçalves, T. C., \&

Magalhães, R. C.

Brito, A. M., \& Dessen, M. A.

Lima, R. P., Maia, R., \& Distler, S. D.

Capovilla, F. C., Raphael, W. D., Viggiano, K., Neves, S. L., \& Luz, R. D.

Fernandes, E.

Siminerio, F. L. P.

Murakami, G. A., Neme, C. M., Yamada, M. O., \& Bevilacqua, M. C.

Bugalho, A. F., Filho., Vieira, D. L., Parreira, M. C., \& Dias, T. R.

Bergmann, L.

Mrech, L. M.

Carvalho, C. D., \& Rafaeli, Y. M.

Kelman, C. A., \& Branco, A. U.

Luz, R. D.

Rezende, I. G., Krom, M., \& Yamada, M. O. 
Bisol, C. A., Simioni, J. \& Sperb, T. (2008). Contribuições da Psicologia Brasileira para o Estudo da Surdez.

2004 Avaliando compreensão de sinais da libras em escolares surdos do ensino fundamental.

2004 A experiência de famílias no convívio com a criança surda.

2004 Identidade, cultura surda e produção de subjetividades e educação: Atravessamentos e implicações sociais.

2004 Uma análise da coesão textual e da estrutura narrativa em textos escritos por adolescentes surdos.

2004 A inclusão sob um olhar especial: A vez e a palavra do educando surdo.

2004 A construção de uma identidade cultural de surdos em parceria com pais ouvintes.

2004 Avaliação psicológica dos efeitos secundários da triagem sistemática da surdez neonatal permanente.

2005 O implante coclear sob a ótica da criança.

2005 O papel do psicólogo no programa de implante coclear do Hospital de Reabilitação de Anomalias Cranofaciais.

2005 Aspectos sociais na produção de distúrbios emocionais em situações de surdez precoce.

2005 Psicologia do desenvolvimento humano, escolarização e língua de sinais: Algumas reflexões.
Capovilla, F. C., Capovilla, A. G., Viggiano, K., \& Bidá, M. C.

Oliveira, R. G., Simionato, M. A., Negrelli, M. E., \& Marcon, S. S.

Cromack, E. M.

Meirelles, V., \& Spinillo, A. G.

Nicolucci, D., Pardo, M. B., \& Dias, T.

Bisol, C.

Le Driant, B., Vandromme, L., Kolski, C., \& Strunski, V.

Nicolau, L. R., Yamada, M. O., \&

Bevilacqua, M. C.

Yamada, M. O., \& Bevilacqua, M. C.

Luz, R. D.

Pimenta, M. L., \& Fávero, M. H.

\section{Resultados e Discussão}

O Conceito de Surdez

Para Johnstone (2001), os conceitos que os pesquisadores têm a respeito de seu objeto de pesquisa definem o tom de seus projetos. Por isso uma das primeiras questões a ser analisada em um trabalho na área da surdez diz respeito à concepção dos autores: a pessoa surda é compreendida a partir de um conceito de deficiência ou de um conceito de diferença cultural? Ou há uma crítica a respeito de ambas as abordagens?

Nos artigos publicados no Brasil e analisados para este estudo encontram-se seis exemplos de pesquisas alinhadas ao modelo clínico-terapêutico, 24 ao modelo socioantropológico e quatro à concepção psicanalítica da surdez. Alguns artigos não explicitam o conceito que estão utilizando. Nestes casos, considerou-se a noção implícita de surdez que pode ser depreendida através da ênfase a aspectos individuais ou sociais, da ênfase à reabilitação, da importância dada à língua de sinais e do referencial teórico utilizado. Para os pesquisadores brasileiros na área da psicologia prevalece, portanto, o modelo socioantropológico. As publicações encontradas referem-se a um período de uma década, de 1995 a 2005. A Figura 1 apresenta o número de publicações ao longo desta década, discriminando por ano de publicação e por conceito de surdez.

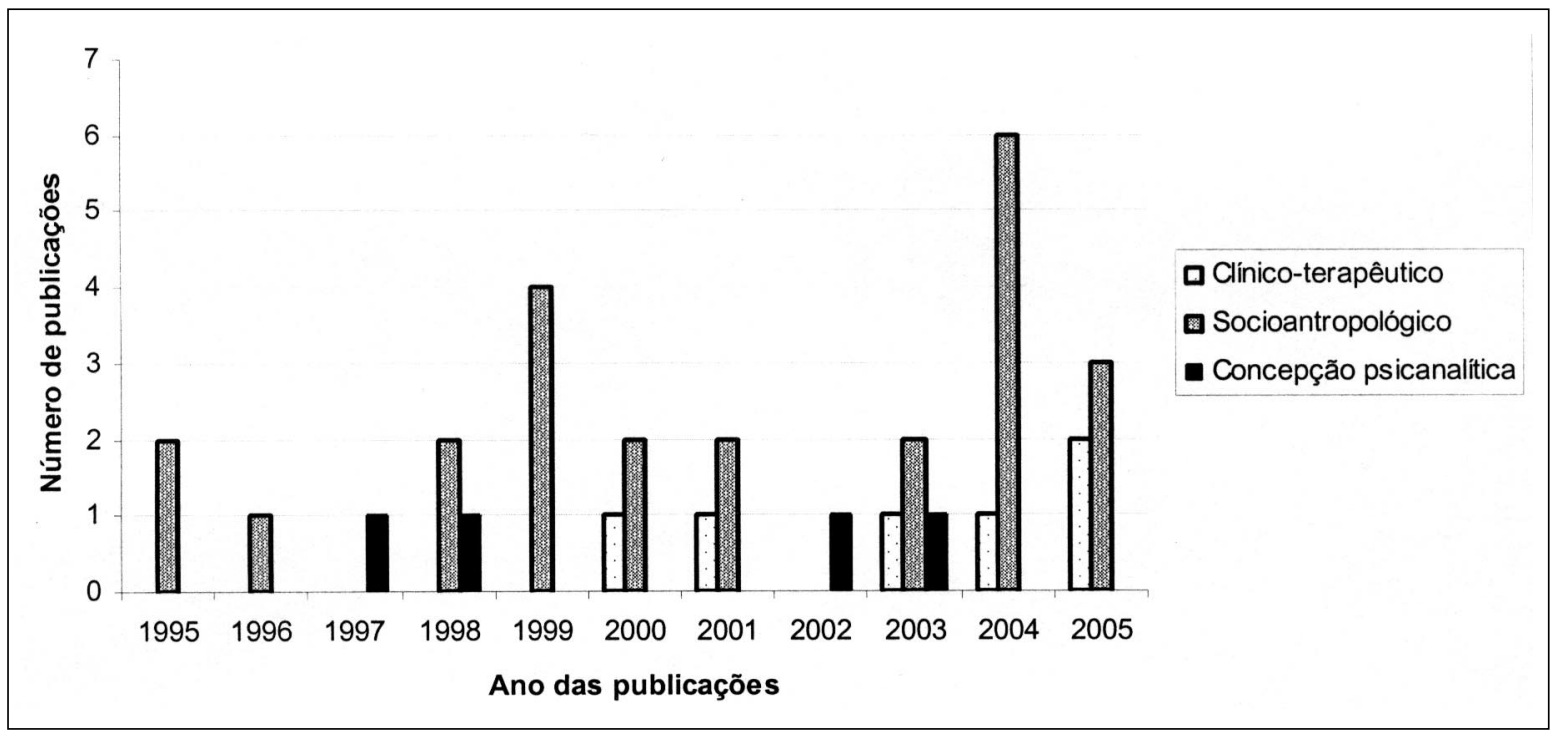

Figura 1. Artigos publicados de 1995 a 2005 
A associação entre a psicologia e o modelo clínicoterapêutico de surdez produz um olhar que tende a enfatizar, no contexto da surdez, o déficit orgânico. As diferenças costumam ser interpretadas como desvio. Percebe-se também uma tendência de compreender os surdos como um grupo homogêneo com desvantagens maturativas inerentes à condição da deficiência. Alguns autores afirmam que existem diferenças neurológicas causadas pela surdez que respondem pelos níveis e agilidade do raciocínio abstrato diferentes entre surdos e ouvintes (Siminerio, 2000). Outros dizem que não há diferenças biológicas entre surdos e ouvintes, mas psicológicas. Afirmam que a consequiência mais devastadora da deficiência auditiva é o impacto causado na identidade, pois isso afeta negativamente as interações sociais, inclusive as familiares (Rezende, Krom, \& Yamada, 2003). Exemplos de problemas no desenvolvimento de crianças surdas por privação do acesso à linguagem costumam ser amplamente citados. Há uma preferência pela utilização dos termos deficiência auditiva e deficiente auditivo, às vezes abreviados simplesmente para d.a.

O período de maior força do modelo clínico-terapêutico na psicologia foi nos anos 50 e 60, quando surgiu a denominação Psicologia da Surdez. O deficiente auditivo era caracterizado como tendo dificuldades motoras, inteligência concreta, lentidão na aprendizagem, agressividade, dificuldade de aceitar limites e impulsividade. Afirmava-se uma relação direta entre as deficiências auditivas e certos problemas emocionais, sociais, lingüísticos e intelectuais, que seriam inerentes à surdez e comuns a crianças, jovens e adultos surdos (Skliar, 1997; Solé, 2004). Em várias publicações sobre o desenvolvimento lingüístico, cognitivo e emocional do surdo, a aquisição da linguagem era associada à aquisição de uma língua oral.

É na década de 60 que o modelo clínico-terapêutico começou a sofrer um profundo questionamento, a partir do trabalho revolucionário de Stokoe sobre a estrutura da Língua Americana de Sinais e de outros estudos de lingüistas demonstrando que as línguas de sinais são línguas naturais e complexas (McCleary, 2003). Observações oriundas do campo da antropologia e da sociologia reforçaram a perspectiva socioantropológica. Segundo Skliar et al. (1995), o modelo socioantropológico está apoiado em duas observações: o fato de que os surdos formam comunidades onde o fator aglutinante é a língua de sinais, e a comprovação de que os filhos surdos de pais surdos apresentam melhores níveis acadêmicos, melhor habilidade para a aprendizagem, e não apresentam os problemas socioafetivos comuns a filhos surdos de pais ouvintes. Nesta perspectiva, questiona-se o discurso da normalidade e procura-se inverter a lógica da adaptação, denunciando o modo como a sociedade "cria" deficiências ao não reconhecer as diferenças ou a restringir o acesso de todos à educação e à saúde. Isto aparece com clareza no artigo de Pimenta e Fávero (2005), pois os autores procuram diferenciar-se do modelo clínico, associado a questões patológicas e padrões de normalidade, e propõem olhar para o surdo como um sujeito em desenvolvimento e não um sujeito limitado pela sua perda.
Esta mudança de paradigma e mais o ressurgimento das contribuições de Vygotsky, a partir da década de 80, introduzem também na psicologia um novo olhar em relação à surdez. Segundo Góes (1999, p. 37), “nessa perspectiva teórica, o desenvolvimento da criança surda deve ser compreendido como processo social, e suas experiências de linguagem concebidas como instâncias de significação e de mediação nas suas relações com a cultura, nas interações com o outro". A autora afirma que não há limitações cognitivas ou afetivas inerentes à surdez, enfatizando as condições sociais da criança surda e as possibilidades para a consolidação da linguagem. Esta autora, assim como Vygotsky, aparece citada em seis artigos analisados.

$\mathrm{Na}$ abordagem socioantropológica, os pesquisadores questionam as perspectivas que não atentam para a variabilidade dos contextos de desenvolvimento das crianças surdas: pais surdos ou ouvintes, perda de audição pré ou pós-lingüística e grau da perda, acesso precoce ou tardio à linguagem, etc. A adequação dos instrumentos de avaliação e o viés introduzido pelo desconhecimento da língua de sinais e das especificidades da população surda passam a ser denunciados como fatores que dificultam os diagnósticos e tratamentos realizados pelos profissionais da saúde.

Nos artigos analisados para este estudo, a predominância do modelo socioantropológico está marcada pela preocupação com a identidade surda, e a palavra surdez é associada a algo que é mais complexo do que a deficiência sensorial em si (Cromack, 2004). Há uma preocupação em situar a relação entre prática psicológica e o conceito de surdez (Souza, 1995, 1998). Embora o termo deficiente auditivo seja por vezes utilizado, percebe-se uma visão não patológica de surdez, com freqüentes conclusões que enfatizam o desenvolvimento sadio do surdo quando dadas as condições sociais e educativas adequadas (Cordeiro \& Dias, 1995; Meirelles \& Spinillo, 2004).

A perspectiva psicanalítica não aparece na literatura convencional como um modelo de concepção de surdez. Nesta análise, porém, considerou-se que ela não corresponde integralmente nem ao modelo clínico-terapêutico nem ao socioantropológico, sendo por isso analisada como uma categoria à parte. Ao situar-se na perspectiva de não tratar a doença, mas o sujeito que, a partir de uma determinada situação, faz um sintoma, a psicanálise estabelece como foco de suas preocupações a constituição subjetiva do surdo e não a cura da surdez (Solé, 2004). Está distante, desta maneira, da preocupação excessiva com a reparação ou cura de algo que seria um déficit a partir de um fato puramente orgânico. Interroga o sujeito a partir de sua singularidade, apontando para a imperfeição de qualquer proposta que pretenda ser global, portanto prescritiva, acerca da psicologia da criança surda (Virole, 2001).

Nos artigos que se destacam pelo viés psicanalítico, os autores não reconhecem um aumento da suscetibilidade à psicopatologia inerente à surdez, mas ao mesmo tempo propõem-se a pensar que a alteração de uma modalidade sensorial acarreta mudanças qualitativas na construção do eu. Um exemplo disso pode ser visto em Solé (1998, p. 21), que começa afirmando que o sujeito surdo não possui 
estruturação psíquica diferente da estruturação dos ouvintes, mas a surdez "marca o destino identificatório de cada sujeito e a privação da fala coloca em perigo a possibilidade de transmissão transgenealógica dos enunciados identificatórios, sustentados pela fala que os pais ouvintes receberam de seus próprios pais". Dentro desta abordagem, o surdo não é situado no mesmo rol das demais deficiências. A situação de estrangeiro que o sujeito surdo vivencia em relação à família e à sociedade é enfatizada (Geovanini, 1997). Em um trabalho mais recente, como o de Carvalho e Rafaeli (2003), o aprendizado da língua de sinais é considerado estruturante para o sujeito.

\section{Temáticas de Maior Interesse}

A Tabela 2 apresenta as principais temáticas desenvolvidas nos artigos analisados neste trabalho. Em alguns casos, há mais de uma temática central, como se pode ver na análise apresentada a seguir, devido ao entrecruzamento de áreas como linguagem e desenvolvimento cognitivo ou constituição da subjetividade e relações familiares, por exemplo.

Tabela 2

Temáticas de Interesse dos Artigos

\begin{tabular}{lc}
\hline Temática & Número de artigos \\
\hline Linguagem e língua & 8 \\
Desenvolvimento cognitivo & 6 \\
Família & 7 \\
Constituição psíquica do sujeito surdo & 5 \\
Processo educativo & 5 \\
Ideologia & 4 \\
Implante coclear & 4 \\
Triagem sistemática de surdez & 1 \\
Musicoterapia & 1 \\
\hline
\end{tabular}

Na temática 'linguagem e língua' foram agrupados os oito artigos que representam uma tríade presente com freqüência nas discussões em torno da surdez: desenvolvimento lingüístico, cognitivo e emocional. A relação entre desenvolvimento lingüístico e cognitivo da criança surda é abordada diretamente em quatro artigos. Destes, dois associam a aquisição da língua de sinais com o desenvolvimento cognitivo do surdo. Fernandes (2000, p. 51), por exemplo, afirma que "saber propiciar a aquisição da Língua de Sinais à criança surda, antes de tudo como respaldo e principal instrumento para o desenvolvimento dos processos cognitivos é o primeiro grande e indispensável passo para a verdadeira educação deste indivíduo”. Já Pimenta e Fávero (2005) apontam para as diferenças entre os processos de representação e construção de significado pelos ouvintes e pelos surdos, devido à diferença entre língua oral e língua de sinais. Os autores, numa perspectiva socioantropológica de surdez, associam as dificuldades cognitivas dos surdos à pobreza comunicativa que caracteriza o sistema educativo. Os outros dois artigos assumem perspectivas um pouco diferentes: Reis (2005) enfatiza tanto o desenvolvimento cognitivo quanto o emocional em suas relações com a linguagem, e Capovilla, Raphael, Viggiano, Neves e Luz (2000) chamam a atenção para o potencial da Sign Writing, uma escrita visual, para acelerar o desenvolvimento lingüístico e cognitivo da criança surda.

Os outros quatro artigos têm enfoque diferente. Carvalho e Rafaeli (2003) e Meirelles e Spinillo (2004) preocupam-se com o aprendizado da língua, da leitura e da escrita pelo surdo. O primeiro enfatiza os processos psíquicos envolvidos a fim de que o acesso à língua de sinais e à escrita alfabética ocorra, e o segundo analisa a coesão textual e a estrutura narrativa em textos escritos por adolescentes surdos. Capovilla, Capovilla, Viggiano e Bidá (2004) apresentam um Teste de Vocabulário Receptivo de Sinais da Libras para avaliar a compreensão de sinais da Libras, e Kelman e Branco (2003) dedicam-se à questão da construção de narrativas em língua de sinais e sua importância na organização e interpretação das experiências interpessoais.

A preocupação com o desenvolvimento cognitivo aparece também em dois trabalhos que não têm como foco de interesse a questão da linguagem. Seminerio (2000) discute, num artigo teórico, o uso da metacognição para o desenvolvimento cognitivo de crianças surdas. Cordeiro e Dias (1995) analisam, numa pesquisa empírica, a capacidade dos deficientes auditivos oralizados e usuários de língua de sinais de resolver problemas silogísticos e comparam com a capacidade dos ouvintes.

A importância do olhar da psicologia sobre a família da criança surda aparece em sete artigos analisados neste trabalho. Em todos eles, a preocupação centra-se na qualidade das interações entre pais ouvintes e filhos surdos e na importância de se compreender a dinâmica e a estrutura familiar. O período do desenvolvimento do membro surdo da família é, em termos gerais, a infância. O impacto do nascimento de uma criança surda é realçado em dois artigos (Brito \& Dessen, 1999; Luz, 2005).

Cinco artigos preocupam-se com a questão da constituição do sujeito surdo, três deles numa perspectiva psicanalítica: Solé (1998) parte das peculiaridades psíquicas que o sujeito surdo enfrenta em sua estruturação e teoriza sobre a escuta analítica oferecida a adolescentes surdos; Mrech (2002) discute alguns dos principais impasses no processo de constituição da criança surda; e Carvalho e Rafaeli (2003) preocupam-se com os processos psíquicos envolvidos a fim de que o acesso à língua de sinais e à escrita alfabética ocorra. A partir de pressupostos um tanto distintos, Bergmann (2001) discute a constituição da subjetividade, especialmente de surdos filhos de pais ouvintes, e Luz (2003) relaciona a construção do psiquismo do sujeito surdo aos caminhos educacionais trilhados até o presente.

A interface da psicologia com a educação é explorada em cinco artigos. A inclusão de alunos surdos em escola regular é problematizada a partir de duas questões: Nicolucci, Pardo e Dias (2004) enfocam a inclusão de alunos surdos em rede pública e concluem que o aluno surdo continua sendo ignorado pela escola em sua necessidade de 
comunicação; Batista e Silva (1996) investigam as concepções e expectativas de pais e profissionais a respeito da opção por escola regular ou escola especial para a criança surda. $\mathrm{O}$ adolescente surdo é contemplado num relato de pesquisa-intervenção sobre estimulação de potencial (Dupret, 1999). Já o interesse de Geovanini (1997) é a escuta psicanalítica lacaniana em instituição escolar para surdos. O quinto artigo a integrar esta categoria é o de Fernandes (2000), também relacionado às categorias da linguagem e língua e desenvolvimento cognitivo.

Em apenas quatro trabalhos verificou-se uma preocupação em situar mais profundamente as implicações ideológicas na discussão da surdez. Estes trabalhos possuem em comum o fato de problematizarem seu objeto de estudo a partir da história da surdez, do lugar que a sociedade tem destinado à deficiência e à surdez, dos modelos de entendimento da surdez (clínico-terapêutico ou socioantropológico) e dos métodos de ensino. São trabalhos interessados na relação entre a psicologia, a educação especial e o bilingüismo (Souza, 1995); na relação entre especialistas ouvintes e sujeitos surdos (Souza, 1998); na identidade (Cromack, 2004) e na família (Luz, 2005).

A questão do implante coclear está ganhando espaço nas publicações brasileiras. A este respeito, Capovilla (1998, p. 76-77) ressalta a "urgente necessidade de pesquisa comparando a eficácia relativa das duas abordagens para o desenvolvimento cognitivo, lingüístico e acadêmico da criança surda: a oralista assistida pelos novos recursos do implante coclear, e a bilíngüe baseada na língua de sinais". Além deste artigo, outros três foram encontrados tratando desse assunto, todos do mesmo grupo de pesquisadores: Murakami, Neme, Yamada e Bevilacqua (2001) estudam as expectativas prévias ao implante coclear e avaliação após implante em adolescentes; Nicolau, Yamada e Bevilacqua (2005) descrevem o implante coclear sob a ótica da criança; e Yamada e Bevilacqua (2005) discutem o papel do psicólogo no programa de implante coclear do Hospital de Reabilitação de Anomalias Craniofaciais.

Há ainda duas temáticas que abordam questões totalmente diferentes das demais. Uma delas é o relato de uma pesquisa de avaliação psicológica dos efeitos secundários da triagem sistemática da surdez neonatal permanente (Le Driant, Vandromme, Kolski, \& Strunski, 2004). A outra, também relato de uma pesquisa, situa-se na área da musicoterapia e investiga a reação de surdos aos instrumentos musicais (Bugalho Filho, Vieira, Parreira, \& Dias, 2001).

\section{Tipo de Publicação}

Dos 34 artigos analisados, três são relatos de experiência, 15 são de revisão da literatura e 16 são relatos de pesquisa empírica. Os relatos de pesquisa foram analisados conforme o tipo de pesquisa (quantitativo ou qualitativo), sendo que um deles define-se como qualiquantitativo exploratório-descritivo.

Dentro do paradigma qualitativo de pesquisa foram encontrados sete artigos: cinco utilizam estudo de caso, embora apenas um deles explicite este delineamento; uma pesquisa utiliza entrevistas semi-estruturadas para coleta de dados e um trabalho relata uma pesquisa-intervenção.
O paradigma quantitativo de pesquisa está representado por oito publicações. De acordo com Nachmias e Nachmias (1996), pode-se classificar estas pesquisas em experimentais e quasi-experimentais com grupos contrastantes. Foram encontrados dois artigos do primeiro tipo e três do segundo. As outras três pesquisas são do tipo survey (Robson, 1993).

A pesquisa realizada por Capovilla et al. (2004) utiliza a maior amostra: os autores aplicaram o Teste de Vocabulário Receptivo de Sinais da Libras para 505 estudantes de 6 a 41 anos de seis escolas de São Paulo. Dos três estudos com grupos contrastantes, um trabalhou com amostra de 80 mães e os outros dois com amostras de 40 e 63 surdos. No caso das entrevistas, as maiores amostras são de 45 e 29 pais. Para os demais estudos, a média dos participantes é de 4,8 por pesquisa, sendo a maior das amostras de 10 participantes. Onze pesquisas foram realizadas com a participação de surdos e cinco com a de mães ou pais de crianças ou adolescentes surdos. A dificuldade para a realização de estudos empíricos em pesquisas com surdos é descrita na literatura internacional. Luckner, Sebald, Cooney, Young III e Muir (2005) explicam que esta dificuldade deve-se à baixa incidência da surdez na população em geral e à imensa heterogeneidade da população surda. Crain e Kluwin (2006) dizem que esta dificuldade leva a uma maior utilização de estudos de caso e estudos etnográficos, correlacionais e comparativos do que de estudos experimentais ou quasi-experimentais.

\section{Considerações Finais}

O objetivo deste estudo foi traçar um panorama das contribuições da psicologia brasileira para o estudo da surdez a partir das publicações encontradas. Pode-se dizer que a produção dos pesquisadores brasileiros é incipiente, pois em uma década (entre os anos de 1995 e 2005) foram encontrados apenas 34 artigos publicados em periódicos científicos nacionais que podem ser considerados contribuições específicas da psicologia ao estudo da surdez. Esta conclusão, no entanto, deve ser relativizada em função das próprias limitações deste estudo. Em primeiro lugar, apesar da busca exaustiva realizada nos meios disponíveis, sabe-se que uma busca mais detalhada em outras bibliotecas universitárias do país poderia revelar a existência de alguns artigos remanescentes. Em segundo lugar, não foi incluída a produção acadêmica expressa em dissertações e teses, o que seria interessante para ampliar a compreensão, principalmente, do potencial de desenvolvimento para as pesquisas nesta área. A análise de trabalhos publicados em livros também poderia trazer contribuições relevantes, assim como a inclusão de autores que não são psicólogos mas que utilizam teorias psicológicas para produzir conhecimento sobre surdez.

Por outro lado, os dados obtidos são significativos. Revelam, por exemplo, uma tendência dos psicólogos brasileiros de optarem pelo modelo socioantropológico de surdez. Também mostram que a psicanálise está presente contribuindo com sua perspectiva para o debate numa área que até então ficava polarizada entre o modelo clínico- 
terapêutico e o modelo socioantropológico. O levantamento referente às temáticas eleitas pelos psicólogos brasileiros abre um campo amplo para se pensar no desenvolvimento desta área no país. Há, por exemplo, um foco significativo no estudo de processos que se situam na infância, com alguns trabalhos seguindo até a adolescência. As temáticas desenvolvidas precisam ser ainda discutidas considerando-se as demais fases do desenvolvimento vital, incluindo estudos com surdos bebês e adultos.

Uma rápida busca na literatura internacional a partir dos portais de pesquisa Wilson e Ovid (http://www.portal dapesquisa.com.br) e dos artigos publicados no American Annals of the Deaf nos anos de 2005 e 2006 revelam, por exemplo, a preocupação dos pesquisadores com a validação de testes para avaliação psicológica de crianças e adolescentes surdos. Com excessão das pesquisas sobre validação de testes de compreensão de sentenças, palavras e sinais (Capovilla et al., 2004), esta questão está ausente das publicações encontradas no Brasil. Outra área importantíssima e ainda não contemplada pelos psicólogos brasileiros diz respeito às especificidades dos processos psicopatológicos, diagnóstico e tratamento de surdos adultos em situação de sofrimento psíquico grave (psicose, depressão, drogadição, etc.). Com exceção de um artigo que pontua questões referentes aos profissionais ouvintes que atendem pessoas surdas e de dois artigos que refletem sobre o possível trabalho do psicanalista com os pacientes surdos, a área da psicologia clínica precisa ainda ser alvo de muita atenção. Pesquisas norte-americanas também questionam a qualidade do atendimento à saúde física e mental da população surda e percebe-se uma preocupação crescente com questões de saúde pública, como DSTs e HIV/ AIDS, o que poderia ser amplamente investigado no Brasil (Barnett, 1999; Harmer, 1999; Job, 2004; Woodroffe, Gorenflo, Meador, \& Zazove, 1998). Em relação à família, a preocupação em compreender a relação dos surdos com os pais ouvintes é ampliada, na literatura internacional, para famílias de pais surdos com filhos ouvintes, pais e filhos surdos, e para a relação entre irmãos. Modalidades de comunicação entre mães ouvintes e bebês surdos ou mães surdas e bebês ouvintes também são áreas exploradas, assim como o implante coclear em crianças.

Em relação ao tipo de publicação brasileira, encontrouse um equilíbrio entre o número de publicações de revisão de literatura e de relato de pesquisa empírica, embora esta última apresente uma série de dificuldades. Para além do problema relativo à obtenção de amostras maiores ou de um número maior de participantes mesmo nas pesquisas qualitativas, há questões metodológicas e éticas. Como a comunidade surda tende a ser pequena e relativamente fechada, a coleta de dados feita através de filmagens de vídeo (mais adequada para capturar a comunicação em língua de sinais) e posterior tradução, exige a utilização de intérpretes, que na maioria das vezes conhecem ou convivem com os participantes das pesquisas. No caso dos pesquisadores não dominarem com fluência a língua de sinais, a dependência exclusiva de intérpretes pode dificultar o acesso e a confiança dos participantes. Os procedimentos éticos que envolvem o consentimento informado podem requerer maior esforço, pois diferenças lingüísticas e culturais podem levar à aceitação no processo de pesquisa sem uma real compreensão das implicações (Pollard, 2002). O nível educacional e social mais baixos da população surda em geral e o acesso limitado a informações através da língua escrita e falada (Barnett, 1999) explicam a maior parte das diferenças lingüísticas e culturais que devem ser ponderadas ao se propor uma pesquisa com esse grupo.

Embora incipiente, pode-se dizer que há uma contribuição importante dos pesquisadores brasileiros para a compreensão de questões relativas à surdez. Estas publicações gradativamente abrem espaço para que novas pesquisas possam ampliar o leque de contextos e temáticas a serem estudados no Brasil na interface da psicologia com a surdez.

\section{Referências}

Bariani, I. C., Buin, E., Barros, R. C., \& Escher, C. A. (2004). Psicologia Escolar e Educacional no ensino superior: Análise da produção científica. Psicologia Escolar e Educacional, 8(1), 17-27.

Barnett, S. (1999). Clinical and cultural issues in caring for deaf people. Journal of Family Medicine, 31(1), 17-22.

Batista, C. G., \& Silva, A. B. (1996). O ingresso da criança surda na escola de primeiro grau: Concepções e expectativas de pais e profissionais. Estudos de Psicologia (Campinas), 13(2), 29-35.

Bergmann, L. (2001). Repercussões da surdez na criança, nos pais e suas implicações no tratamento. Informativo TécnicoCientífico Espaço INES, 16, 3-8.

Brito, A. M., \& Dessen, M. A. (1999). Crianças surdas e suas famílias: Um panorama geral. Psicologia: Reflexão e Crítica, 12(2), 429-445.

Bugalho, A. F., Filho, Vieira, D. L, Parreira, M. C., \& Dias, T. R. (2001). Musicoterapia e surdez: A reação de surdos aos instrumentos musicais. Temas Sobre Desenvolvimento, 9(54), 28-34.

Capovilla, F. C. (1998). O implante coclear como ferramenta de desenvolvimento lingüístico da criança surda. Revista Brasileira de Crescimento e Desenvolvimento Humano, 8(1/2), 26-88.

Capovilla, F. C., Capovilla, A. G., Viggiano, K, Q., \& Bidá, M. C. (2004). Avaliando compreensão de sinais da libras em escolares surdos do ensino fundamental. Interação em Psicologia, 8(2), 159-169.

Capovilla, F. C., Raphael, W. D., Viggiano, K., Neves, S. L., \& Luz, R. D. (2000). SignWriting: Implicações psicológicas e sociológicas de uma escrita visual direta de sinais, e de seus usos na educação do surdo. Informativo Técnico-Científico Espaço INES, 13(1), 31-37.

Carvalho, C. D., \& Rafaeli, Y. M. (2003). A língua de sinais e a escrita - Possibilidades de se dizer, para o surdo. Estilos da Clínica, 8(14), 60-67.

Coordenação de Aperfeiçoamento de Pessoal de Nível Superior. (2004). Classificação de periódicos, anais, revistas e jornais. Brasília, DF: Ministério da Educação. Retrieved from http:// servicos.capes.gov.br/webqualis/

Cordeiro, A. A., \& Dias, M. G. (1995). O raciocínio lógico-dedutivo do surdo que se utiliza da linguagem gestual ou oral. Psicologia: Teoria e Pesquisa, 11(3), 193-202.

Crain, K. L., \& Kluwin, T. N. (2006). The validity of probability samples in research on deafness. American Annals of the Deaf, 151(2), 114-120. 
Cromack, E. M. (2004). Identidade, cultura surda e produção de subjetividades e educação: Atravessamentos e implicações sociais. Psicologia: Ciência e Profissão, 24(4), 68-77.

Ducharme, D., \& Mayberry, R. I. (in press). L'importance de l'exposition précoce au langage: le périod critique s'appliqué au langage signe tout comme au langage orale. In C. Transler, J. Leybaert, \& J. E. Gombert (Eds.), Le développment du langage chez l'enfant sourd, le signe, la parole et l'écrit. Bruxelles, Belgium: De Boeck \& Larcier.

Dupret, L. (1999). Integração do sujeito ao processo educativo na realidade contemporânea: Um estudo com adolescentes surdos. Informativo Técnico-Científico Espaço INES, 10, 3-9.

Fernandes, E. (2000). Língua de sinais e desenvolvimento cognitivo de crianças surdas. Informativo Técnico-Científico Espaço INES, 13, 48-51.

Ferreira, N. S. (2002). As pesquisas denominadas "estado da arte". Educação e Sociedade, 23(79), 257-272.

Geovanini, F. C. (1997). Da psicanálise à surdez - Uma escuta psicanalítica em instituição escolar para surdos. Informativo Técnico-Científico Espaço INES, 8, 16-20.

Góes, M. C. (1999). Linguagem, surdez e Educação (2. ed.). Campinas, SP: Autores Associados.

Harmer, L. M. (1999). Health care delivery and deaf people: Practice, problems and recommendations for change. Journal of Deaf Studies and Deaf Education, 4(2), 74-110.

Job, J. (2004). Factors involved in the ineffective dissemination of sexuality information to individuals who are deaf or hard of hearing. American Annals of the Deaf, 149(3), 264-273.

Johnstone, D. (2001). An introduction to disability studies. London: David Fulton.

Kelman, C. A., \& Branco, A. U. (2003). Era uma vez...: Narrativas literárias em língua de sinais como fator de desenvolvimento. Linhas Críticas, 9(16), 33-42.

Le Driant, B., Vandromme, L., Kolski, C., \& Strunski, V. (2004). Avaliação psicológica dos efeitos secundários da triagem sistemática da surdez neonatal permanente. Revista Brasileira de Crescimento e Desenvolvimento Humano, 14(2), 29-33.

Luckner, J. L., Sebald, A. M., Cooney, J., Young, J., III, \& Muir, S. G. (2005). An examination of the evidence-based literacy research on deaf education. American Annals of the Deaf, $150(5), 443-455$.

Luz, R. D. (2003). Violência psíquica e surdez - Os caminhos de um (des)encontro. Informativo Técnico-Científico Espaço INES, 20, 3-12.

Luz, R. D. (2005). Aspectos sociais na produção de distúrbios emocionais em situações de surdez precoce. Informativo Técnico-Científico Espaço INES, 24, 3-19.

Marchesi, A. (1993). El desarrollo cognitivo y lingüístico de los niños sordos. Madrid, España: Alianza Psicología.

McCleary, L. (2003). Technologies of language and the embodied history of the deaf. Sign Language Studies, 3(2), 104-124.

Meirelles, V., \& Spinillo, A. G. (2004). Uma análise da coesão textual e da estrutura narrativa em textos escritos por adolescentes surdos. Estudos de Psicologia (Natal), 9(1), 131-144.

Mrech, L. M. (2002). Um olhar psicanalítico a respeito da questão da identidade do surdo. Informativo Técnico-Científico Espaço INES, 17, 3-11.

Murakami, G. A., Neme, C. M., Yamada, M. O., \& Bevilacqua, M. C. (2001). Expectativas prévias ao implante coclear e avaliação após implante em adolescentes. Estudos de Psicologia (Campinas), 18(2), 5-16.

Nachmias, C. F., \& Nachmias, D. (1996). Research methods in the social sciences. London: St. Martin's Press.
Nicolau, L. R., Yamada, M. O., \& Bevilacqua, M. C. (2005). O implante coclear sob a ótica da criança. Temas sobre Desenvolvimento, 14(80/81), 61-67.

Nicolucci, D., Pardo, M. B., \& Dias, T. (2004). A inclusão sob um olhar especial: A vez e a palavra do educando surdo. Temas sobre Desenvolvimento, 13(76), 19-24.

Padden, C., \& Humphries, T. (1988). Deaf in America: Voices form a culture. London: Harvard University Press.

Pimenta, M. L., \& Fávero, M. H. (2005). Psicologia do desenvolvimento humano, escolarização e língua de sinais: Algumas reflexões. Informativo Técnico-Científico Espaço INES, 23, 75-81.

Pollard, R. Q. (1993). 100 years in psychology and deafness: A centennial retrospective. Journal of the American Deafness and Rehabilitation Association, 26(3), 32-46.

Pollard, R. Q. (2002). Ethical conduct in research involving deaf people. In V. A. Gutman (Ed.), Ethics in mental health and deafness. Washington, DC: Gallaudet University Press.

Reis, V. P. (2005). A linguagem e seus efeitos no desenvolvimento cognitivo e emocional da criança surda. Informativo Técnico-Científico Espaço INES, 6, 23-38.

Rezende, I. G., Krom, M., \& Yamada, M. O. (2003). A repetição intergeracional e o significado atual da deficiência auditiva. Psicologia: Teoria e Pesquisa, 19(2), 177-184.

Robson, C. (1993). Real world research: A resource for social scientists and practitioner-researchers. Oxford, UK: Blackwell.

Siminerio, F. L. (2000). Metacognição: Um caminho para ultrapassar os limites da audição. Informativo Técnico-Científico Espaço INES, 14, 23-36.

Skliar, C. (1997). Uma perspectiva sócio-histórica sobre a Psicologia e a Educação dos surdos. In C. Skliar (Ed.), Educação \& Exclusão: Abordagens sócio-antropológicas em educação especial. Porto Alegre, RS: Mediação.

Skliar, C., Massone, M. I., \& Veinberg, S. (1995). El acceso de los ninos sordos al bilingüismo y al biculturalismo. Infancia y Aprendizaje, 2(69), 85-100. Retrieved June, 13, 2005, from http://virtual.udesc.br/html/surdos/artigos/artigo04.htm

Solé, M. C. (1998). A surdez enquanto marca constitutiva. Informativo Técnico-Científico Espaço INES, 9, 17-23.

Solé, M. C. (2004). A surdez e a Psicanálise: O que é dito. In A. S. Thoma \& M. C. Lopes (Eds.), A invenção da surdez: Cultura, alteridade, identidade e diferença no campo da educação. Santa Cruz do Sul, RS: Editora da Universidade de Santa Cruz do Sul.

Souza, R. M. (1995). Educação especial, Psicologia do surdo e bilingüismo: Bases históricas e perspectivas atuais. Temas em Psicologia 2, 71-87.

Souza, R. M. (1998). Sujeito surdo e profissionais ouvintes: Repensando esta relação. Estilos da Clínica. Revista sobre a Infância com Problemas, 3(4), 130-145.

Virole, B. (2001). Développement psychologique de l'enfant sourd: moments critiques. Retrieved January, 16, 2004, from http://www.benoitvirole.com

Woodroffe, T., Gorenflo, D. W., Meador, H. E., \& Zazove, P. (1998). Knowledge and attitudes about AIDS among deaf and hard of hearing persons. AIDS Care, 10(3), 377-386.

Yamada, M. O., \& Bevilacqua, M. C. (2005). O papel do psicólogo no programa de implante coclear do Hospital de Reabilitação de Anomalias Craniofaciais. Estudos de Psicologia (Campinas), 22(23), 255-262.

Recebido: 17/01/2007

$1^{a}$ revisão: $11 / 07 / 2007$ Aceite final: 01/12/2007 